\title{
ENSINO ONLINE DAS QUATRO HABILIDADES DA LÍNGUA INGLESA EM UM CURSO DE LICENCIATURA EM LETRAS A DISTÂNCIA: UM RELATO DE EXPERIÊNCIA
}

\author{
UBERABA/MG JULHO/2018 \\ Luciana Góis Barbosa - Uniube - gestor.letras@uniube.br \\ Renata de Oliveira Souza Carmo - Uniube - renatadeoliveira.carmo@gmail.com \\ Eliana Rossetti Sardinha - Uniube - eliana.sardinha@uniube.br \\ Tipo: Relato de Experiência Inovadora (EI) \\ Categoria: Suporte e Serviços \\ Setor Educacional: EDUCAÇÃO SUPERIOR
}

\begin{abstract}
RESUMO
Este estudo tem por objetivo relatar a experiência referente ao uso da plataforma online do curso de inglês Voxy na disciplina "Atividade Prática de Língua Inglesa" de um curso de licenciatura em Letras na modalidade $E A D$. Fundamenta-se em revisão bibliográfica a fim de embasar a investigação no que se refere ao processo de ensino e aprendizagem desse idioma mediado por tecnologias. Usa, como metodologia, o estudo dialético apoiado na pesquisa do tipo observação participante, que permitiu constatar o estranhamento inicial dos cursistas ante a nova proposta de prática online da língua inglesa e que a intervenção imediata dos professores da disciplina foi preponderante para a reversão daquela relutância. Conclui que o acompanhamento docente de uma disciplina online, somado ao apoio dos pares da docência em EAD, é fundamental para o aprimoramento de sua oferta, o que incentiva a aprendizagem, especialmente de uma língua estrangeira.
\end{abstract}

Palavras-chave: Língua Inglesa. Ensino. AVA. EAD. 


\section{Introdução}

Este relato de experiência tem como tema o ensino de língua estrangeira (LE) mediado por novas tecnologias em um curso de licenciatura em Letras na modalidade a distância. Experiências na docência desse idioma necessitam ser compartilhadas pela relevância da língua inglesa em um mundo globalizado e interconectado, mas, apesar disso, observa-se seu baixo domínio nas quatro habilidades linguísticas pela população brasileira em geral. Nesse sentido, é fundamental que o professor de LE tenha consistente formação inicial no idioma a ser ensinado na educação básica. Assim sendo, o objetivo deste estudo foi relatar a busca do corpo docente de um curso de Letras na modalidade a distância por implementar uma disciplina prática de língua inglesa em ambiente virtual de aprendizagem (AVA) em parceria com a plataforma online de cursos de inglês, Voxy[1].

\section{As tecnologias no ensino de língua inglesa}

Com a chegada da internet na década de 1990 e a sua disseminação nos últimos 20 anos, houve significativa modificação das estruturas sociais no que diz respeito ao acesso às informações e às possibilidades de comunicação. Na educação, não foi diferente, pois as tecnologias de informação e comunicação (TIC) passaram a ser recursos assíduos nas salas de aula: aparelho de som, CD, videocassete, DVD, computador, pendrive, notebook, tablet, smartphone, wi-fi, data-show; enfim, uma série de tecnologias que foram sendo acrescentadas ao cotidiano do processo de ensino e aprendizagem (SILVA, 2006).

A partir da diversificação das TIC e do acesso à internet, a educação a distância (EAD) incorporou esses recursos às suas práticas educativas, o que aproximou essa modalidade de valores do tempo presente, tais como flexibilidade, interação, autonomia, inovação. Assim, dos estudos baseados no material impresso e na comunicação postal ou telefônica, a EAD se apropriou das novas tecnologias, especialmente a internet, a fim de diversificar materiais didáticos - livro eletrônico, vídeo-aula, animação etc. - e de possibilitar interações síncrona e assíncrona entre professor/ aluno e aluno/ aluno por meio de canais diversos - e-mail, chat, fóruns, videoconferências etc. (MOORE; KEARSLEY, 2007).

Adicionalmente, esse percurso tecnológico trilhado pela EAD permite uma reflexão acerca dos estudos de uma LE nessa modalidade. Segundo Paiva (2015), a incorporação de tais recursos à aprendizagem autônoma de línguas atravessa os tempos, pois, desde as gramáticas e as listas de vocabulário no século XVI, passando 
pela radiodifusão no século $X X$, chegou-se à possibilidade de prática interativa $e$ colaborativa de um idioma estrangeiro a partir do acesso, compartilhamento e produção de conteúdo na língua-alvo com o apoio da internet, disponibilizada nos anos 1990 e melhorada nos anos 2000.

A partir disso, criou-se um recurso tecnológico de interação e comunicação, conectado em rede e com finalidade educativa, o ambiente virtual de aprendizagem (AVA). Essa sala de aula online permite o desenvolvimento do processo de ensino e aprendizagem a partir de ferramentas comunicacionais síncronas e assíncronas que viabilizam a interação, o arquivamento, o compartilhamento e o gerenciamento de informações, além de materiais didáticos escritos e audiovisuais (BITTENCOURT, 2013). Em seu projeto educacional, um programa de EAD pode optar por um AVA gratuito, como o Moodle[2], ou desenvolver seu próprio ambiente online a partir do trabalho coletivo de sua equipe multidisciplinar - professores, analistas, designers, pedagogos etc.

Por seu potencial de interação e flexibilidade, nas últimas décadas, as tecnologias digitais vêm sendo incorporadas a diferentes práticas sociais. No entanto, Cani et al. (2017) alertam que as práticas escolares ainda têm dificuldades em incorporar tais recursos ao seu processo formativo; sendo que, no caso do ensino de uma LE, popularizam-se meios informais de aprendizagem, como os aplicativos para celulares, pela oportunidade de uma experiência mais autônoma e horizontal com a língua-alvo. Ademais, os autores ressaltam a necessidade de critério didático-pedagógico na seleção das interfaces tecnológicas de modo a permitir sua fácil navegação pelos usuários e a aplicação da LE em situações que considerem seu uso social.

Evidencia-se, portanto, a variedade de recursos didáticos que podem ser usados com a finalidade de ensinar e de aprender, mesmo quando professores e cursistas estão em tempos e espaços diversos. Quanto aos cursos de LE a distância, estes passaram a ter mais possibilidades de vencer dificuldades ante uma prática interativa e comunicativa da oralidade no idioma estudado. No entanto, Cani et al. (2017) ressaltam que as TIC poderão contribuir com o aprimoramento do ensino de LE a partir do desenvolvimento de práticas que evidenciem a aprendizagem colaborativa e autônoma.

Nessa perspectiva, a diversidade e a interatividade são estimuladoras das mídias eletrônicas que despertam o interesse daqueles que as acessam. No entanto, Harmer (2009) alerta que, em se tratando de cursos de idiomas a distância, os alunos precisam se sentir motivados e orientados em sua aprendizagem e, para isso, a presença e a interação dos professores no AVA são fundamentais. O autor acrescenta que, apesar das vantagens do estudo a distância em plataformas online, a falta do contato face a 
face é fator desestimulante para o estudo a distância, especialmente de uma LE.

Ao se revisitar o percurso das tecnologias como recursos para o ensino e a aprendizagem de uma LE a distância, reforça-se a necessidade da sistematização de práticas formativas do idioma inglês, lingua franca do tempo presente, pois contatos linguísticos nesse idioma - cinema, música, jornalismo, turismo, ciência etc. - se tornaram mais frequentes, especialmente após o advento da internet (ELLIS, 2008). O registro e a reflexão de experiências educativas de língua inglesa mediadas pelas TIC poderão contribuir com uma formação interativa, colaborativa e crítica dessa língua-alvo, cujo ensino é obrigatório na educação básica brasileira, mas que permanece associada a uma aprendizagem descontextualizada baseada na repetição, na tradução e na memorização.

\section{O caminho metodológico}

Este relato de experiência teve como objetivo apresentar a oferta de uma disciplina prática de língua inglesa em um curso de Letras a distância junto a cursistas situados nas cinco regiões brasileiras[3]. Nessa modalidade, um dos desafios dos cursos de formação de professores em LE é promover o ensino e a aprendizagem da língua-alvo com vistas ao seu domínio para o desenvolvimento de práticas educativas na educação básica. Embora o aprendizado de uma LE em ambiente online seja ainda permeado por questões afetivas, culturais e tecnológicas, este estudo teve como propósito relatar a experiência dos professores desse curso na proposição e na condução de uma disciplina prática de língua inglesa em parceria com a plataforma online de cursos de inglês, Voxy.

Essa disciplina foi intitulada "Atividade Prática da Língua Inglesa", sendo obrigatória na grade curricular dessa licenciatura em Letras, na modalidade a distância. Sua finalidade é o desenvolvimento das competências básicas do idioma inglês - listening, speaking, reading e writing - em articulação com diferentes textos das modalidades oral e escrita ao longo de 20 semanas de estudos. O papel do curso de inglês é oferecer conteúdos e atividades que atendam à necessidade formativa desse projeto de licenciatura. Para isso, esse parceiro, em sua plataforma online, cujo atalho foi disponibilizado na sala de aula da disciplina no AVA institucional, disponibiliza unidades de estudo semanais para o exercício de itens linguísticos a partir de textos com temáticas atuais, tutorias em grupo com tutores fluentes ou nativos na língua inglesa para a prática da oralidade e momentos avaliativos para nivelamento e verificação do desempenho do aluno no decorrer do curso. 
Os conhecimentos e as habilidades construídos nas práticas desenvolvidas na plataforma associada poderão ser aplicados no desenvolvimento da "Prática Laboratorial On-line / Podcast", uma atividade já realizada pelo curso de Letras em estudo, que consiste na gravação de um arquivo de áudio digital - o podcast. A partir das orientações fornecidas por uma gravação do professor sobre o tema a ser contemplado na exposição oral do aluno, este deverá gravar um áudio na língua inglesa, que será postado no AVA, por meio do software criado pela equipe TIC da instituição, para avaliação pelo professor vinculado ao curso de Letras desse programa de EAD. No semestre, são realizados dois podcasts. Fazem parte dos critérios de avaliação eventuais erros, sejam eles lexicais, gramaticais ou de pronúncia; velocidade da fala; entonação; pontuação; espontaneidade; fluência no idioma estrangeiro e vocabulário adequado ao tema proposto.

Anteriormente a essa proposta, a prática de língua inglesa nesse curso de licenciatura em Letras se caracterizava pela realização de encontros presenciais nos polos de apoio ou transmitidos via internet com duração de quatro horas-aula, que aconteciam duas vezes no semestre. Além de mobilizar recursos físicos e humanos, esses eventos requeriam um professor licenciado em Letras e com domínio da língua inglesa a fim de mediar o processo de ensino e aprendizagem, tendo-se em vista as necessidades formativas do acadêmico para a docência desse idioma na educação básica.

Diante disso, este relato de experiência se constitui como um trabalho de abordagem qualitativa apoiado na metodologia de estudo dialética, uma vez que "[...] todos os aspectos da realidade (da natureza ou da sociedade) prendem-se por laços necessários e recíprocos", o que "[...] leva à necessidade de avaliar uma situação, um acontecimento, uma tarefa, uma coisa, do ponto de vista das condições que os determinam e, assim, os explicam" (MARCONI; LAKATOS, 2017, p.102). Como técnica de investigação, realizou-se a observação participante que, segundo Martins (2000, p.29), é um tipo análise na qual "[...] a presença do observador numa situação social é mantida para fins de investigação científica [...], logo, o observador é parte do contexto que está sendo observado, no qual ele ao mesmo tempo modifica e é modificado por este contexto". Desse modo, a seguir, apresenta-se o relato do corpo docente de língua inglesa desse curso de licenciatura na modalidade a distância ao implementar uma disciplina prática daquela LE em ambiente online.

\section{Uma experiência de ensino de língua inglesa em AVA: apresentação e discussão}

O curso de licenciatura em Letras, com habilitação em língua inglesa, foi lançado no ano de 2005 pelo Programa de Educação a Distância em estudo. Em referência à formação 
para a docência dessa língua-alvo, é seu objetivo licenciar um professor-educador para atuar nos anos finais do ensino fundamental e ensino médio, com domínio disciplinar e pedagógico no ensino do idioma. Para isso, almeja-se que a prática da língua inglesa nesse curso de licenciatura possibilite ao graduando a construção de conhecimentos elementares que permitam a interação e a produção de textos orais e escritos no idioma[4].

De sua oferta inicial até o presente, foram propostas diferentes estratégias para a prática dessa língua-alvo, além dos estudos e das atividades a distância realizadas nas disciplinas de língua inglesa, metodologia do ensino de língua estrangeira e literatura de língua inglesa. Dentre as experiências mais marcantes, destacaram-se as oficinas presenciais nos polos de apoio e as videoconferências em tempo real via internet. Em relação às primeiras, seus principais inconvenientes foram a escassez de professores qualificados para mediá-las, especialmente em regiões afastadas dos centros mais desenvolvidos. Em relação às segundas, seus principais obstáculos foram a necessidade de equipamentos técnicos e profissionais de tecnologia; além do fato de que os cursistas, nos polos, assistiam e participavam das atividades práticas, sendo o contato com o professor-mediador viabilizado pela interface tecnológica. Do ponto de vista do exercício da língua inglesa, ambas propostas aconteciam duas vezes no semestre, o que levava a uma prática intermitente da oralidade no idioma estrangeiro.

Em fevereiro de 2017, foi apresentada aos discentes a parceria entre o curso de Letras / EAD e o curso online de inglês Voxy por meio da disciplina "Atividade Prática de Língua Inglesa", ofertada semestralmente durante os quatro anos da licenciatura. Além da oportunidade de acessá-la a partir de dispositivos eletrônicos conectados em rede; com o apoio da plataforma parceira, essa disciplina pôde oferecer práticas ininterruptas no uso da língua inglesa a partir da disponibilização de conteúdos autênticos e atuais em conformidade com o domínio linguístico do cursista. Com isso, foi possível melhorar a oferta de input, amostras de linguagem escrita e falada a que o aprendiz deve ser exposto para aprender a LE (ELLIS, 2009). Na disciplina proposta, essa aprendizagem passou a auxiliar o cursista na produção de seu podcast, texto de caráter autoral na modalidade falada da língua inglesa.

Em sua dinâmica, a nova disciplina apresentou elementos necessários à prática de LE em meio online, tais como a acessibilidade, a variedade, a autenticidade e a interatividade. No entanto, como destacou Paiva (2015), antes da aceitação, o ingresso de uma nova forma de tecnologia no contexto educacional pode ser marcado pela rejeição ou pela incompreensão. Os últimos foram sentimentos demonstrados pelo corpo discente e, com os quais, o corpo docente da disciplina teve que lidar. 
A proposição, a elaboração e a implementação da disciplina contemplaram momentos, presenciais e não presenciais, de discussão entre os professores de língua inglesa, a gestão do curso de Letras, a coordenação pedagógica do programa de $E A D$, a equipe de tecnologia e o representante do curso de inglês, para que a incorporação desse último atendesse ao projeto pedagógico da licenciatura em Letras e ao programa de EAD. Esses encontros possibilitaram ao corpo docente compreender o desenho da nova disciplina, o que levou à preparação de materiais para orientação e motivação dos estudantes, tais como videoaula, orientações semanais de estudos e mensagens enviadas pelos professores, gestão de curso e equipe TIC/ EAD; além dos próprios direcionamentos e serviços de apoio da plataforma parceira. Ainda assim, os estranhamentos se mostraram recorrentes, como ilustram as seguintes mensagens enviadas aos professores pelo AVA:

"Bom dia! Não consigo entrar no portal, como eu faço?" - Cursista na semana 2 da disciplina "Atividade Prática de Língua Inglesa" (1º semestre / 2017)

"Achei confusa essa disciplina no portal, nunca sei que atividade devo fazer (se posso escolher qualquer uma...). Será que ainda há pontos a serem distribuídos o suficiente para eu ser aprovada na disciplina?" - Cursista na semana 11 da disciplina "Atividade Prática de Língua Inglesa" (1ํsemestre / 2017)

Mesmo no contexto da EAD mediada pelas TIC, o professor permanece como referência a quem o aluno recorre em momentos de dificuldade. Além disso, embora a docência seja uma atividade caracterizada pelo ensino de uma disciplina, o estudante, sem o entendimento do funcionamento de seu curso, poderá ter sua aprendizagem comprometida. Pelo conhecimento do programa de EAD, do projeto pedagógico do curso, da disciplina proposta e do ambiente online, somada à interação com os discentes no AVA, o corpo docente desse curso de Letras se dedicou a encontrar maneiras de contribuir com o estabelecimento da confiança na disciplina recém-iniciada.

Diante do volume de questionamentos relativos ao acesso e ao uso da plataforma online de língua inglesa associada ao curso de Letras, às atividades avaliativas a serem realizadas e ao sistema de avaliação da disciplina, o corpo docente se reuniu a fim de encontrar meios de oferecer aos seus estudantes os esclarecimentos necessários. Uma alternativa viável foi a elaboração de um FAQ[5], com perguntas e respostas a partir de triagem feita pelo corpo docente das dúvidas mais comuns enviadas pelos cursistas pelo AVA. Essas indagações foram reescritas de modo objetivo para facilitar a compreensão e as respostas para elas foram elaboradas após consultas aos setores competentes - 
curso de inglês, TIC / EAD ou gestão do curso, por exemplo - a fim de se garantir a exatidão das informações.

Ao se buscar essas respostas junto aos demais pares do processo de ensino e aprendizagem da língua inglesa, possibilitou-se a compreensão conjunta de como a disciplina poderia se constituir a fim de contemplar os projetos da licenciatura, do AVA institucional, do programa de EAD e do curso online de inglês. Essas consultas resultaram em melhor domínio da dinâmica da disciplina pelos envolvidos e, ao mesmo tempo, permitiu o aprimoramento de seu desenho e a correção de eventuais falhas na sua publicação na sala de aula online. $O$ apoio e a abertura dos profissionais da gestão, da tecnologia e da plataforma foram fundamentais para sanar os apontamentos relatados pelos discentes, construindo-se, assim, o estímulo necessário ao ato educativo. O documento final apresentou nove perguntas e respostas, tendo sido compartilhado no AVA com os cursistas em fins de março de 2017. Após essa ação, os relatos enviados passaram a conter reações como as seguintes:

"Gostei muito dessa plataforma. É dinâmica, e os textos com as atividades são muito bem-escolhidos." - Cursista na semana 9 da disciplina "Atividade Prática de Língua Inglesa" (1ํㅗ semestre / 2017)

"[...] estou fazendo 02 participações no grupo [de tutoria] por semana, e 19 lições semanais [...] estou aproveitando a oportunidade." - Cursista na semana $10 \mathrm{da}$ disciplina "Atividade Prática de Língua Inglesa" (1º semestre / 2017)

Após a publicação do $F A Q$, o corpo docente percebeu expressiva redução no recebimento de mensagens de incompreensão diante da nova proposta. Para o ano letivo de 2018, esse documento foi atualizado e disponibilizado aos cursistas no AVA, sendo que dúvidas de ordem técnica e/ou acadêmica têm se mostrado ocasionais. Assim, a função primordial do professor é planejar, conduzir e avaliar o processo de ensino e, nesta experiência em relato, o acompanhamento e a intervenção do corpo docente foram pontuais para que ajustes fossem feitos na oferta da disciplina, o que impediu o desânimo dos cursistas ante o estudo de uma LE a distância.

\section{Considerações finais}

Este relato de experiência apresentou a atuação do corpo docente de um curso de Letras / EAD na resolução de dúvidas e incertezas de seus cursistas ante uma disciplina prática de língua inglesa a distância, que passou a ser ofertada no primeiro semestre letivo de 2017. Seu diferencial foi a parceria firmada com uma plataforma online de 
cursos de inglês capaz de oferecer conteúdos e práticas autênticos, flexíveis e interativos. A despeito dessas vantagens, observou-se o estranhamento e a insegurança dos alunos quanto ao uso da plataforma integrada ao AVA institucional. A estreita observação e a pronta intervenção do corpo docente, em conjunto com os demais pares desse projeto, foram essenciais para $o$ aprimoramento da oferta da nova disciplina. Nesse sentido, um instrumento simples, como o FAQ, foi capaz de orientar os discentes quanto ao processo de ensino e aprendizagem da língua inglesa; além de demais recursos para esse fim que continuaram sendo utilizados, tais como videoaulas, orientações de estudos, tutoriais, mensagens semanais, serviços institucional e Voxy de atendimento ao aluno etc. Com isso, espera-se que os estudantes desse curso de Letras tenham a oportunidade de praticar, com constância e flexibilidade, a língua inglesa em suas quatro habilidades, o que poderá resultar em uma formação linguística mais sólida para sua atuação docente na educação básica. As TIC são ferramentas de grande auxílio na EAD, mas o processo educacional reafirma seu caráter complexo, humano e afetivo, qualquer que seja a modalidade e o nível de ensino. Por isso, experiências de ensino de LE em ambiente online devem ser sistematizadas e compartilhadas.

\section{REFERÊNCIAS}

BITTENCOURT, C. P. N. Identidade e subjetividade docente no ambiente virtual de aprendizagem ressignificando a prática pedagógica. 2013. 100 f. Dissertação (Mestrado em Educação) - Universidade de Brasília, Brasília, 2013. Disponível em: <http://repositorio.unb.br/handle/10482/13382>. Acesso em: 16 jul. 2016.

CANI, J. B.; PINHEIRO, I. Q.; SANTIAGO, M. E. V.; SOARES, G. M. Análise de jogos digitais em dispositivos móveis para aprendizagem de línguas estrangeiras. Rev. bras. linguist. apl., Belo Horizonte, v. 17, n.3, p. 455-481, 2017. Disponível em: < http://www.s cielo.br/scielo.php?pid=S1984-63982017000300455\&script=sci_abstract\&tlng=pt>. Acesso em: 10 jul. 2018.

ELLIS, R. Second language acquisition. Oxford: Oxford University Press, 2008.

HARMER, J. How to teach English. Essex: Pearson Longman, 2009.

MARCONI, M. A.; LAKATOS, E. M. Fundamentos de metodologia científica. 8. ed. São Paulo: Atlas, 2017. 
MARTINS, G. A. Manual para elaboração de monografias e dissertações. 2. ed. São Paulo: Atlas, 2000.

MOORE, M.; KEARSLEY, G. Educação a distância: uma visão integrada. São Paulo: Cengage Learning, 2007.

PAIVA, V. L. M. O. O uso da tecnologia no ensino de línguas estrangeiras: breve retrospectiva histórica. In: JESUS, D. M.; MACIEL, R. F. (Org.). Olhares sobre tecnologias digitais: linguagens, ensino, formação e prática docente. Campinas: Pontes Editores, 2015. p. 21-34. Disponível em: $<$ http://www.veramenezes.com/techist.pdf>. Acesso em: 11 maio 2018.

SILVA, M. Educação online: teorias, práticas, legislação, formação corporativa. 2. ed. São Paulo: Edições Loyola, 2006.

[1] Curso totalmente online e personalizado de língua inglesa, com aulas em tempo real, professores de inglês nativos e conteúdos atualizados diariamente.

[2] Acrônimo para a expressão inglesa Modular Object-Oriented Dynamic Learning Environment ou, em português, Ambiente de Aprendizagem Dinâmico Modular Orientado a Objeto.

[3] Segundo informações disponibilizadas no sítio eletrônico dessa instituição de ensino superior, seu programa de EAD possui polos em 14 estados brasileiros, além do Distrito Federal; totalizando 104 polos que oferecem, atualmente, o curso de Letras.

[4] Informações disponibilizadas no Projeto Pedagógico do curso.

[5] FAQ - acrônimo da expressão inglesa Frequent Asked Questions ou "Perguntas Mais Frequentes". Refere-se a um documento público para consulta dos usuários de determinado serviço. 